\title{
Investigating capacities and barriers of Iranian medical universities in developing entrepreneurship in terms of educational experts: A content analysis study
}

\author{
Solmaz Sadat Naghavi Alhosseini ${ }^{1}$, Ata Pourabbasi $^{2 *}\left(\mathbb{D}\right.$, Sevil Banay Razi ${ }^{3}$
}

Received: 27 Oct 2018

Published: 20 Mar 2021

\section{Abstract}

Background: Entrepreneurship leads to an increase in national income by creating new jobs and plays a role as a positive factor in economic growth by serving as a bridge between innovation and the market. The aim of this study was to identify the capacity and barriers existing in the medical universities of Iran to develop entrepreneurship from the viewpoint of some of the officials and academic experts.

Methods: This qualitative, descriptive-analytic study was conducted to explore threats and opportunities in educational entrepreneurship at medical universities. The sample consists of medical universities' deputies of education across the country, attending the national meeting of education deputies. A questionnaire containing 10 open questions was tailored and given to the participants. After returning the questionnaires, the responses were evaluated using the content analysis method.

Results: The issues related to the strengths of the medical universities in entrepreneurship development can be summarized in 3 categories: human factors, organizational and infrastructure factors, and technical and technological factors. With regard to the existing weaknesses while developing entrepreneurship in the context of medical universities, there are 3 general categories: education and research barriers, state-legal-political, and economic-managerial shortcomings.

The barriers to entrepreneurship development among medical graduates can be categorized in 4 groups, including education and information, cultural and social factors, financial barriers as well as structural and infrastructural drawback.

Conclusion: The most important movement toward entrepreneurship development in medical universities could be making structural revisions in transforming into third-generation universities. This important issue is being pursued and implemented by the government in the form of Plan for Development and Innovation in Medical Education.

Keywords: Entrepreneurship, Entrepreneurial University, Barriers of Entrepreneurship, Entrepreneurship Development

Conflicts of Interest: None declared

Funding: None

*This work has been published under CC BY-NC-SA 1.0 license.

Copyright $\odot$ Iran University of Medical Sciences

Cite this article as: Naghavi Alhosseini SS, Pourabbasi A, Banay Razi S. Investigating capacities and barriers of Iranian medical universities in developing entrepreneurship in terms of educational experts: A content analysis study. Med J Islam Repub Iran. 2021 (20 Mar);35:37. https://doi.org/10.47176/mjiri.35.37

\section{Introduction}

Entrepreneurship refers to those behaviors that have

Corresponding author: Dr Ata Pourabbasi, atapoura@tums.ac.ir

1. Department of Idea Development and Innovation Center, Endocrinology and Metabolism Research Institute, Tehran University of Medical Sciences, Tehran, Iran

2. Endocrinology and Metabolism Research Center, Endocrinology and Metabolism Clinical Sciences Institute, Tehran University of Medical Sciences, Tehran, Iran

3. Department of Drug Quality Assurance, Faculty of Pharmacy, Pharmaceutical Sciences Branch, Islamic Azad University, Tehran, Iran signs of initiative and creative thinking, through which

\section{$\uparrow$ What is "already known” in this topic:}

Entrepreneurship education is highly important because of the high unemployment rates in the community. The main movement toward entrepreneurship development in Iranian medical universities is transforming into third-generation universities, which has been considered in the Development and Innovation Plan in Medical Education.

\section{$\rightarrow$ What this article adds:}

In this paper, authors have tried to collect strengths and weaknesses and the opportunities for entrepreneurship development in Iranian medical universities with the view of academic experts and provide valid evidence for policymakers in this field. 
social and economic mechanisms are organized to transform resources and situations into the acceptance of risks and failures and to orient the marketplace (1). Policy makers in Europe and the United States argue that entrepreneurship not only leads to an increase in national income by creating new jobs but also plays a role as a positive factor in economic growth by serving as a bridge between innovation and the market (2).

Entrepreneurship is a critical notion in organizations and institutions, including universities (3). The experiences of various countries of the world, both developed and developing, have indicated that the best option for preparing the educated individuals for future employment in the labor market is to create an appropriate framework for self-employment and entrepreneurship in the context of academia (4).

The entrepreneurial university is a theoretical perspective highlighted in the $20^{\text {th }}$ century, which draws special attention to the highly interactive role of universities with the society. Therefore, the higher education system should be coordinated with business development and labor market by making changes in educational programs (5).

In this regard, the topic of entrepreneurship has been considered in the Development and Innovation plan in Medical Education by the Ministry of Health and Medical Education. This plan has been developed in the form of 11 packages, one of which is moving toward third-generation universities. The target areas of this package include the structural reengineering of medical universities in moving toward third-generation universities, promotion of entrepreneurship, and creating knowledge-based wealth in medical universities.

According to this policy, universities must try to educate entrepreneurs and familiarize the faculty members and medical students with the entrepreneurial and business skills to institutionalize these concepts in the community (6).

In its global higher education perspective in the $21 \mathrm{st}$ century, the UNESCO has defined the modern universities as the place where entrepreneurial skills in higher education are developed to facilitate graduates' capacities and assist them to become entrepreneurs (7).

Many graduates do not obtain the entrepreneurial skills needed to enter the job market because of the lack of right training in the education system. With regard to the number of educated young people and the lack of job opportunity, entrepreneurship education and the creation of entrepreneurial culture in higher education institutions may be a valuable way of developing entrepreneurial thinking and, consequently, reducing the unemployment, which is a serious concern of the society (8).

With over 19000 faculty members in more than 60 medical universities in the country, Iran's Health System trains around 200000 students and produces one third of knowledge and training of the specialist staff. Researchers and faculty members of the medical universities of Iran produce about one-third of Iran scientific papers on a yearly basis. Therefore, in the current situation, the country needs creative and innovative students who can use theoretical understanding of a subject to generate knowledge and create wealth and social welfare.

Considering the importance of entrepreneurship and the role of medical universities in its development, it is necessary to identify the existing capacities and obstacles. In general, the models and frameworks of entrepreneurial universities can be classified into 2 approaches:

A. An attitude focused on the entrepreneurship aspects of entrepreneurial universities.

B: An approach that emphasizes the factors affecting the formation of entrepreneurial universities (9).

In this study, the second view was taken. The first step in creating and developing an entrepreneurial university is to investigate the influential factors and barriers of entrepreneurship in universities. Based on this, the present study was designed and implemented to identify the capacity and barriers existing in the medical universities of Iran to develop entrepreneurship from the viewpoint of some of the officials and academic experts. It seems that collecting these views and classifying them at different levels can provide policymakers with the necessary information to provide groundwork for the realization of the third-generation universities or entrepreneurial universities more than ever.

\section{Methods}

This study was an applied research in terms of purpose and a descriptive-analytic in terms of data collection, which was conducted both quantitatively and qualitatively to investigate the capacities and existing barriers in the medical sciences universities of Iran for the development of entrepreneurship.

The research population included deputies of education at medical universities across the country who attended the national meeting of deputies of education, each with an employment background of education, management, counseling, policy-making, and executive responsibilities.

In order to collect information based on the objectives of the study, a questionnaire containing 10 open questions was tailored and was given to the participants. The survey questions included the definitions of entrepreneurship in the field of health, strengths and weaknesses of medical universities in entrepreneurship development, the most important barriers to entrepreneurship among health education graduates, reasons for the need for entrepreneurship development at the current time, the supportive role of the headquarters and universities in entrepreneurship development, the role of other institutions in the development of entrepreneurship, and, finally, the proposed strategies for the development of entrepreneurship. In this research, the strengths and weaknesses of medical universities in the development of entrepreneurship and the most important barriers of entrepreneurship in health graduates were studied.

Also, the respondents were asked to indicate the name of the province in which they work, their academic level, duration of managerial occupations in the field of education, and a brief history of their university.

After the questionnaires were returned, the responses were evaluated using the content analysis method. Opensource coding was done, which included reading respons- 
es in a line by line fashion, extracting main concepts and sentences, forming categories and primary classes, and axial coding, including classification of data, specification of subclasses, and formation of final classes. Data were entered into the excel software. Further to qualitative evaluation, these codes were statistically analyzed using a descriptive method.

\section{Results}

A total of 66 questionnaires were distributed among the participants, and objectives of the study were explained to them through written and oral instructions. Finally, 29 questionnaires were returned. On average, medical education managers had 9.25 \pm 7.24 years of experience. A participant from Isfahan University of Medical Sciences with
23 years' experience had the most experience in our sample. Of the respondents, $24.2 \%$ were full professors, $37.9 \%$ associate professors, and $37.9 \%$ assistant professors. On average, universities were founded 41.5 years ago, with Tehran University of Medical Sciences, with 83 years of run time, being the oldest.

Based on the findings, the issues related to the strengths of medical universities in entrepreneurship development can be summarized in 3 categories: human factors, organizational and infrastructure factors, and technical and technological factors (Table 1).

Concerning the existing weaknesses, while developing entrepreneurship in the context of medical universities, there are 3 general categories: education and research barriers, state-legal-political, and economic-managerial shortcomings (Table 2).

Table 1. Strengths of medical universities in entrepreneurship development

\begin{tabular}{|c|c|}
\hline Category & Prepositions \\
\hline Human factors & 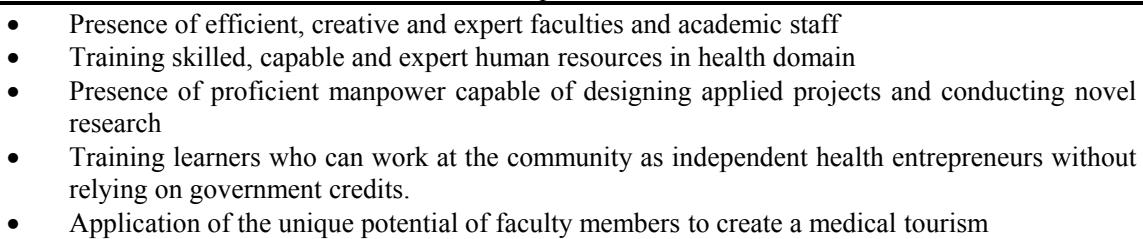 \\
\hline $\begin{array}{l}\text { Organizational and infrastruc- } \\
\text { ture factors }\end{array}$ & 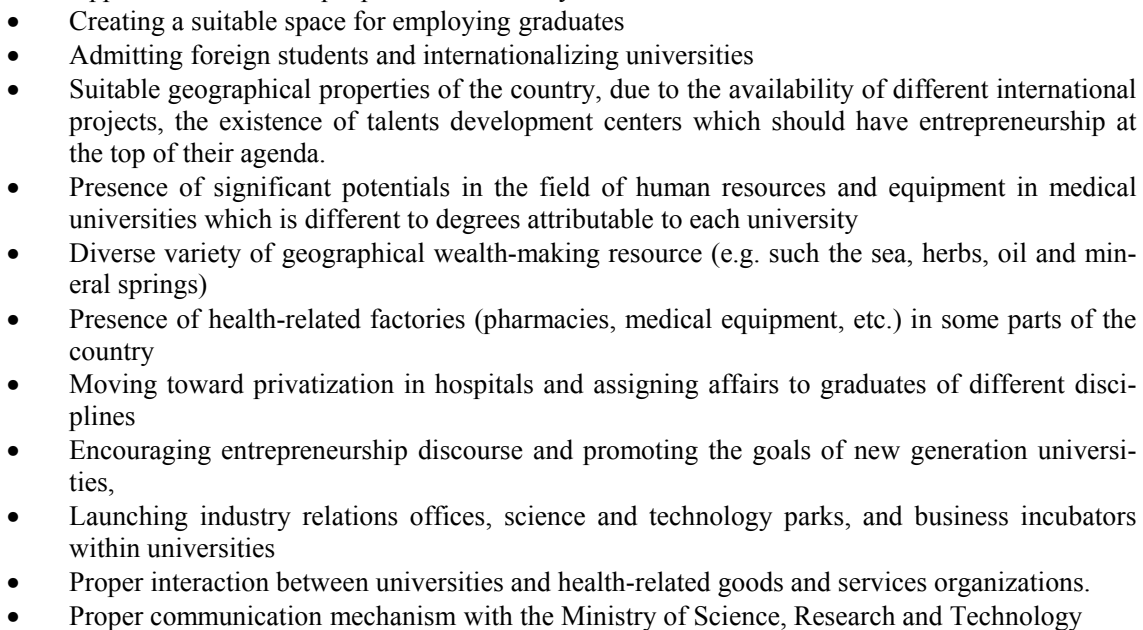 \\
\hline $\begin{array}{l}\text { Technical and technological } \\
\text { factors }\end{array}$ & $\begin{array}{l}\text { - Applicable nature of medical sciences and the possibility of technological innovation and re- } \\
\text { verse engineering of medical equipment manufacturing, } \\
\text { - } \quad \text { Rapid growth of modern technologies and the continuous improvement of these processes, } \\
\text { - } \quad \text { Applying new treatment methods in the shortest time since the invention } \\
\text { - } \quad \text { Protecting high-tech healthcare products against excessive imports. }\end{array}$ \\
\hline
\end{tabular}

Table 2. Weaknesses of medical universities in entrepreneurship development

\begin{tabular}{|c|c|}
\hline Categories & Prepositions \\
\hline Education and research & $\begin{array}{l}\text { Lack of training of faculties on entrepreneurship and their unfamiliarity with the entrepreneurial } \\
\text { university } \\
\text { - Using traditional teaching methods } \\
\text { - } \quad \text { Defects in interdisciplinary training programs } \\
\text { - } \quad \text { Lack of specialists familiar with third-generation universities } \\
\text { Less attention to research }\end{array}$ \\
\hline State-legal-political & 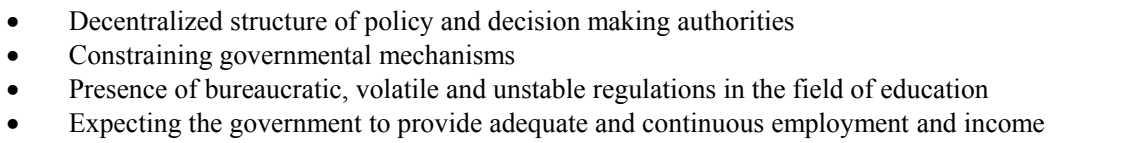 \\
\hline Economic-managerial & $\begin{array}{l}\text { - } \\
\text { - } \\
\text { - } \\
\text { - Lack of independence in the management areas } \\
\text { Lack of financial management in the health system }\end{array}$ \\
\hline
\end{tabular}


Table 3. Barriers to entrepreneurship development among medical graduate

\begin{tabular}{|c|c|}
\hline Category & Prepositions \\
\hline Education and information & $\begin{array}{l}\text { - } \quad \text { Inadequate training on entrepreneurship at university } \\
-\quad \text { No fundamental revision in educational curricula } \\
\text { - Lack of familiarity of managers, teachers, parents, and learners with the dimensions and im- } \\
\text { portance of entrepreneurship in the field of health }\end{array}$ \\
\hline Cultural and social factors & $\begin{array}{l}\text { - Lack of proper culture of entrepreneurship in the community and universities } \\
\text { - } \quad \text { Fack of standard health patterns that have an enforceable warranty } \\
\text { - Lack of social support from entrepreneurs }\end{array}$ \\
\hline Financial barriers & $\begin{array}{l}\text { - Tendency to easy money-earning methods like medication and nursing in the public or private } \\
\text { - sector } \\
\text { - Lack of investment security and high risk of failure } \\
\text { - Lack of liquidity needed to create knowledge-based companies or services } \\
\text { Lack of financial support for entrepreneurial ideas by funds and financial institutions }\end{array}$ \\
\hline Structural and infrastructural & $\begin{array}{l}\text { - Lack of necessary ground for linking graduates with outside areas of the university } \\
\text { - } \quad \text { Feeling of job insecurity } \\
\text { - Lack of service leveling and the multiplicity of alumni employment } \\
\text { - } \quad \text { documents and long-term goals } \\
\text { Disparity between the level of academic literacy and the ability of graduates, } \\
\text { - Inadequate employment opportunities in society } \\
\text { - Unwillingness to work in less developed areas } \\
\text { Incompliance of the major policies of education and higher education development with the } \\
\text { needs of the community considering the existence of numerous universities } \\
\text { Failure to use and localize the experience of successful universities of developed countries }\end{array}$ \\
\hline
\end{tabular}

The barriers to entrepreneurship development among medical graduates can be categorized into 4 groups: including education and information, cultural and social factors, financial barriers, and structural and infrastructural drawbacks (Table 3).

\section{Discussion}

This research was conducted with the aim of investigating the existing capacities and barriers in the medical universities of Iran for the sake of entrepreneurship development from the viewpoint of the academic experts. The main strength of this study could be attributed to gathering the views of a number of experts who are simultaneously responsible for the education department of medical universities. All participants, in addition to their faculty membership, were well acquainted with the strengths and weaknesses of the university and the obstacles in the development of entrepreneurship by virtue of their organizational position.

An entrepreneurs university provides opportunities for the formation of creative entrepreneurship and profitable business models through raising the level of entrepreneurial knowledge, implementing creative ideas and solutions, advancing the students' research towards entrepreneurship, training competent and expert entrepreneurs in the field of health, as well as planning and delivering entrepreneurship topics in the curriculum of all majors of medical sciences, increasing research in the health system, promoting the proper interaction between the university and the health-related goods and services bodies, and, finally, providing appropriate supportive mechanisms (ie, financial, legal, equipment, etc.) (10).

The realization of the third generation of universities requires the provision of entrepreneurial education in all disciplines and faculties. Perhaps the main mission of the university is merely the transfer of a series of academic concepts, namely, research and knowledge transfer, but in the present era, the university is no more just a place to learn a series of academic concepts and to perform industrial and commercial projects, but it is a place to educate innovative and creative graduates who are perceived as a major source for investment and development of the community. Such individuals create business opportunities through employing their knowledge besides conducting applied research (11).

Since the establishment of an entrepreneurial university in all medical universities is not possible in the short term, it is possible to prepare the necessary structure for an entrepreneurial higher education institution through examining the obstacles and capacities of the universities. Doing so, an entrepreneurial environment could be prepared aided by health-related professional teams, information support, financial advisory, and facility provision (11).

One of the main implications of this study is the abundant competencies of the universities of medical sciences in the development of entrepreneurship, which suggest that by proper management and the timely and proper use of these capabilities, we can soon witness the development of entrepreneurship among the alumni of medical universities (12).

Our study showed that from the perspective of academic experts, economic and managerial factors are one of the important weaknesses of medical universities in the development of entrepreneurship, which is consistent with Ehsanifar et al's study. They proposed some strategies for the development of entrepreneurship among which are the following: reforming government policies and regulations, educating and promoting entrepreneurship, providing material support, such as granting tax incentives and lowinterest loans, and, ultimately, providing nonmaterial sup- 
port, such as launching the business incubators and providing amenities and physical facilities (13).

Moghadasi et al have also concluded some factors affecting the entrepreneurship of medical universities, among which one can name prioritizing entrepreneurship in the strategic planning of the university, entrepreneurship management in higher education, organizing training courses for entrepreneurship, providing financial resources, promoting the spirit and culture of entrepreneurship, encouraging entrepreneurs' alumni associations, providing facilities and extracurricular activities, and inclusion of entrepreneurship in the academic curricula. Each of the aforementioned factors has been emphasized in the viewpoint of respondents in the present study (14).

In a research conducted by Farsi Jahangir et al, the organizational factors affecting academic entrepreneurship in Iran include as follows: (a) rules, structure and governance of the university; (b) entrepreneurship and business training programs; (c) university-industry relationship; (d) governmental policies and regulations; (e) intellectual property laws; and (f) educational and research structure of the university. Principle informal institutional factors are as follows: (g) method of enforcing rules; (h) political considerations; (i) role models and academic reward system; and (j) academicians' attitudes toward entrepreneurship. However, in the present study, such classification pattern has not been incorporated among the factors influencing academic entrepreneurship, but the results are, to some degree, compatible with each other (15). Ayegba et al have proposed the availability of credit facilities and exposure to modern technology as the encouraging forces of the entrepreneurship development in universities (16).

Amini et al also conducted a research on the strengths and weaknesses of university entrepreneurship wherein they investigated 6 factors: political forces; financial and economic contexts; cultural and social backgrounds; support; institutions; networks and interactions; and human capital. Further, they introduced institutional supports as well as networks and interactions as the most important strengths and support factor as the rarest strength point in the path to academic entrepreneurship. In addition, political forces and financial and economic contexts were interpreted as the most important barrier and support factors as the least important in the course of the creation of university entrepreneurship (17).

The results of this study to identify the weaknesses of medical universities in entrepreneurship development is consistent with those of Jafarinejad et al (18), Samitowska (19), Ayodeji (20), Chowdhury et al (21), and Atif Bashir (22).

In the present study, among the strengths and weaknesses of universities as well as the leading factors, the academic scholars have made no reference to intellectual property rights, commercialization, family role, and the curriculum revision. This is while Hamilton has emphasized on intellectual property laws and commercialization practices as an important organizational factor (23). In addition, Casillas have pinpointed to the family involvement as an underlying factor in the success and development of entrepreneurship (24). Dundar \&Merc also drew the attention to the necessity of changing and reviewing the curriculum (25).

\section{Conclusion}

The results of this study showed that to encourage entrepreneurship behavior, universities must first highlight the benefits of expanding capabilities and seeking opportunities and then continue with realizing the opportunities.

Finally, given the fact that universities in Iran are not in a proper position in terms of entrepreneurship, it seems that by looking at the results of this study, it would be possible to come up with solutions to realize this mission in medical universities.

Due to the large number of apprenticeship programs in medical sciences, it is recommended to establish a strong link between the apprenticeship programs and entrepreneurship goals through the formulation of related regulations.

Also, by organizing conferences and workshops and visiting entrepreneurship activities, the university can strengthen the motivation, training, and entrepreneurship skills among students.

As with other universities in developed countries, entrepreneurship and innovation activities are considered as one of the key indicators in the assessment process of faculty members. It is also necessary to provide the necessary facilities for the presence of faculty members in the industry and to facilitate their communication with organizations outside the university to reflect research and educational needs.

Along with all these measures, the most important movement toward entrepreneurship development in medical universities could be making structural revisions in transforming into third-generation universities. This important issue is being pursued and implemented by the government in the form of the Plan for Development and Innovation in Medical Education (26).

\section{Acknowledgment}

We would like to thank Dr Seyed Amin Kouhpayeh and Dr Iraj Nabi Pour who have helped us to develop this study with their valuable guidance.

\section{Conflict of Interests}

The authors declare that they have no competing interests.

\section{References}

1. Bujor A, Avasilcai S. The creative entrepreneur: A framework of analysis. Proced Soc Behav Sci. 2016;221:21-28.

2. Oosterbeek H, Van Praag M, Ijsselstein A. The impact of entrepreneurship education on entrepreneurship skills and motivation. Eur Econ Rev. 2010; 54(3): 442-454.

3. Yıldırım N, Askun OB. Entrepreneurship intentions of public universities in Turkey: going beyond education and research? Proced Soc Behav Sci. 2012;58:953-963.

4. Sabet Maharlouei A. Factors influencing academic entrepreneurial intention among The students of shiraz Medical Sciences University. J Med Educ Dev. 2014;7(15):71-85.

5. Boyles T. $21 \mathrm{st}$ century knowledge, skills, and abilities and entrepreneurial competencies: A model for undergraduate entrepreneurship education. J Entrepreneur Educ. 2012;15:41-56 
6. Pourabbasi A, Akbari H, Akhavan AA, Haghdoost AA, Kheiry Z, Dehnavieh R, et al. Analysis of Iran's National Medical Education Evolution and Innovation Plan using the Michelle and Scott's model of policymaking. J Adv Med Educ Prof. 2019;7(1):20-26

7. Sam C, Van Der Sijde P. Understanding the concept of the entrepreneurial university from the perspective of higher education models. High Educ. 2014;68(6) 891-908.

8. Mason G, Williams G, Cranmer S. Employability skills initiatives in higher education: what effects do they have on graduate labour market outcomes? Educ Econ. 2009;17(1):1-30.

9. OConnor A. A conceptual framework for entrepreneurship education policy: Meeting government and economic purposes. J Bus Ventur. 2013;28(4):546-563.

10. Niccum BA, Sarker A, Wolf SJ, Trowbridge MJ. Innovation and entrepreneurship programs in US medical education: a landscape review and thematic analysis. Med Educ Online. 2017;22(1):1-7.

11. Philpott K, Dooley L, O'Reilly C, Lupton G. The entrepreneurial university: Examining the underlying academic tensions. Technovation. 2011;31(4):161-170

12. Madsen EL. Entrepreneurship and dynamic capabilities an empirical testing. Int J Technol Intell Plan. 2012;8(4):317-332.

13. Ehsanifar T, Rostami F, Naderi N, Rezaee B. Obstacles and Strategies for Entrepreneurship Development in the Agricultural Sector. J Entrepren Agrica. 2016;3(2):1-15.

14. Moghadasi J, Keikavoosi AM, Keikavoosi AL. Factors Affecting the Transformation of Medical Sciences Universities into Entrepreneurial Universities in Iranian Higher Education System. J Health Manag. 2016;6(4):49-59

15. Salamzadeh A, Yadollahi Farsi J, Motavaseli M, Radovic-Markovic M, Kawamorita Kesim H. Institutional factors affecting the transformation of entrepreneurial universities. Int $\mathrm{J}$ Bus Glob. 2015;14(3):271-291.

16. Ayegba O, Omale SA. A study on factors affecting entrepreneurial development in Nigeria. Eur J Bus Manag. 2016;8(12):43-51.

17. Amini M, Jamshidi R, Heydarinejad S. Prioritization of Entrepreneurship Barriers of Physical Education Students by TOPSIS Method. J Med Cultiv. 2014;2(6):15-32.

18. Jafarnejad A, Abbaszadeh MA, Ebrahimi M, Abtahi SM. Analysis of Barriers to Entrepreneurship in Small and Medium-sized Enterprises (SMEs). Int J Acad Res Econ Manah Sci. 2013;2(4):207-216.

19. Samitowska W. Barriers to the development of entrepreneurship demonstrated by micro, small and medium enterprises in Poland. Econ Sociol. 2011;4(2):42-49.

20. Ayodeji M. Entrepreneurial development barriers in a developing nation: A case study of the Nigerian Printing SMEs [dissertation]: Applied Scienses Univ; 2015.

21. Chowdhury MS, Alam Z, Arif MI. Success factors of entrepreneurs of small and medium sized enterprises: Evidence from Bangladesh. Bus Econ Res. 2013;3(2):38-52.

22. Atif Bashir M. Entrepreneurship Barriers to Student in Southern Punjab Universities. Int J Manag Bus Res. 2015;5(4):329-335.

23. Hamilton MT. Exploring intervention to the regional institutions for innovation: Technology-based economic development [dissertation]: Carnegie Mellon Univ; 2008.

24. Casillas JC, Moreno AM. The relationship between entrepreneurial orientation and growth: The moderating role of family involvement. Enterpren Reg Dev.2010;22(3-4):265-291.

25. Dundar E, Merc A. A Critical Review of Research on Curriculum Development and Evaluation in ELT. Eur JFLT. 2017;2(1):136-168.

26. Pourabbasi A, Haghdoost AA, Akbari H, Kheiry Z, Dehnavieh R, Noorihekmat $\mathrm{S}$, et al. Packages for reform and innovation in medical education in Islamic Republic of Iran; a conceptual framework. J Med Cultiv. 2017;26(1):45-50. 